\title{
Women and Substance Use: An Overview for Nurses
}

\author{
Janice Sanders ${ }^{1}$ \\ ${ }^{1}$ California State University, Fresno, USA \\ Correspondence: Janice Sanders, California State University, Fresno, USA.
}

Received: September 7, 2018

doi:10.20849/ijsn.v3i3.480
Accepted: September 24, $2018 \quad$ Online Published: September 28, 2018

URL: https://doi.org/10.20849/ijsn.v3i3.480

\begin{abstract}
Substance use is a major health concern among women, as approximately 15.8 million have used an illicit drug in the past year. Another 4.3 million have misused prescription drugs. Men are more likely to engage in illicit drug use than women, however, the gender gap is narrowing. The consequences of substance abuse not only negatively impact women, but may affect the cognitive and physical abilities of their children. For methodology, electronic searches were conducted using scholarly databases with various combinations of keywords related to women, substance abuse, addiction, nursing care, pregnancy, and gender difference. Research trends indicate that women often present with gender-specific needs, including physiologically, socially, and economically. This article gives an overview of some gender differences between men and women and how they influence treatment and outcomes for women. It also discusses special considerations for nurses caring for women with substance use disorders.
\end{abstract}

Keywords: women, substance abuse, addiction, nursing care, pregnancy, gender difference

Substance use is a health concern in the United States. In 2017, the Center for Behavioral Health Statistics and Quality reported that more than 27 million people in the United States reported current use of an illicit drug or misuse of prescription drugs in the past 30 days (Substance Abuse and Mental Health Services Administration [SAMHSA], 2017a). Another 80 million people are risky substance users, using alcohol and drugs in ways that threaten their health and safety (National Center on Addiction and Substance Abuse at Columbia University [CASA Columbia], 2012). The United States spent \$28 billion to treat addiction (CASA Columbia; "author" \& Russler, 2014) and research shows that 15.8 million women, ages 18 or older, engaged in illicit drug use in the past year (SAMHSA, 2017b; National Institute on Drug Abuse, 2018). Substance use can lead to adverse outcomes for women and adversely impact their health, families, and socioeconomic status. The complexity of gender presents unique challenges when caring for women with substance use disorders (SAMHSA, 2017a).

Women sometimes encounter negative attitudes and stigma when seeking care for substance use disorders or addictions (Alexander, 2017; Chu \& Galang, 2013; Puskar et al., 2013). Healthcare professionals' attitudes toward patients who report substance use directly affect the recovery success and health outcomes (Alexander, 2017). Negative attitudes may influence one's willingness to engage and develop a therapeutic nurse-patient relationship, contributing to suboptimal care. Supportive and positive healthcare experiences can motivate patients to seek ongoing medical care and treatment for their substance use disorders or addictions (Chu \& Galang, 2013). Nurses need to understand the disease of addiction and the gender-specific needs of women in order to provide optimal care and improve recovery outcomes.

\section{Epidemiology}

Historically, men have had higher rates of substance abuse than women; however, the gap between them has been narrowing worldwide (Grant et al., 2016; Grosso et al., 2013; McHugh, Votawa, Sugarman, \& Greenfield, 2017; Sanders," 2014). Internationally, the epidemiology of substance use disorders varies. Policies and culture influence the accessibility and acceptability of substance use. Findings from the World Health Organization (WHO) World Mental Health Survey indicated that less traditional roles correlate with smaller gender gaps. When the gender role was less traditional, women began to "catch up" with men in terms of substance use disorders (Grant et al., 2016; Seedat et al., 2015).

More recently, the National Epidemiological Survey on Alcohol and Related Conditions (NESARC) did a study on drug use disorders and found $4.9 \%$ for men and 3.0\% for women for any drug use (Grant et al., 2016). The most commonly used drugs were cannabis, opioids, and cocaine (Grant et al., 2016). For stimulants, there were 
no differences in use between men and women. Several studies indicated that the rates were higher for women than for men, particularly with narcotic analgesics and sedatives (Grant et al., 2016; Grella, 2008).

In the early 1980s, the male to female ratio of alcohol use disorders was estimated to be 5:1. Surveys succeeding this reported the ratio as 3:1 (Greenfield, Back, Lawson, \& Brady, 2010). In 2015, an estimated 47.2\% of females, 12 and older, reported alcohol use in the past month, compared to $56.2 \%$ for males (SAMHSA, 2017b). Women tended to binge less often than men. Usually, adult men showed a greater use of alcohol and more problematic behavior, such as binge drinking and alcohol abuse. Data showed no gender gap among adolescent boys and girls, ages 12-17. Regarding alcohol, the current use has been $9.9 \%$ for girls and $9.6 \%$ for boys. For binge drinking, the amount has been 5.8\% for both genders (CBHSQ, 2016; McHugh et al., 2017).

\section{Gender Differences}

Despite using smaller doses in shorter periods of time, when compared to men, women experience more severe clinical complications (McHugh et al., 2017; Office on Women's Health [OWH], 2017). One reason is due to a phenomenon known as telescoping. Telescoping is an accelerated progression from the initiation of substance use to the onset of dependence and first admission to treatment (McHugh et al., 2017; OWH, 2017). It has been reported that men were 2.2 times more likely than were women to use drugs and 1.9 times more likely to become drug dependent (Greenfield et al., 2010). Biological factors may also increase the adverse effects of substance abuse. Women have lower percentages of total body water, decreased first pass metabolism, and slower rates of alcohol metabolism (National Institute on Drug Abuse [NIDA], 2018, Sanders, 2014). Basic and clinical studies have shown that estrogen increases and progesterone decreases potentiate the effects of stimulants (Greenfield et al., Sanders, 2014). Biological factors adversely influence metabolism, as well as a rapid progression to addiction.

Mortality rates for women who abuse substances are also greater than for men. Women who abuse alcohol are twice as likely to die from abuse-related health problems. Also, women who smoke are three times more likely than men to die of lung cancer. Even more astounding, the number of women dying from addiction related illnesses is four times the number of women who die from breast cancer (Young, 2010). The health impact on women has been significant.

In addition to physiological factors, psychosocial factors differ between men and women. Women are more likely to have relatives with substance use problems, as well as spouses who use drugs. It is more likely that women will initiate hazardous drug use while in intimate partner relationships after being introduced to substances by boyfriends or spouses (OWH, 2017). Additionally, initiation of substance among women has been linked to histories of traumatic childhood events involving physical and sexual abuse, usually by people the women knew and trusted (Cleveland, Bonugli, \& McGlothen, 2016; OWH, 2017).

\section{Effects of Children and Parenting}

More than 8 million children younger than 18 years have lived with at least one parent who is dependent on drugs and/or alcohol in the past year (Anna, Mericle, Meyers, \& Winters, 2012; Sanders \& Russler, 2014). Additionally, it is estimated that $50-80 \%$ of child welfare system cases involve parents who abuse alcohol or other drugs, with mothers making up the majority of the substance-abusing parents in the child welfare system (Nichols et al., 2012; Sanders \& Russler, 2014). Substance abuse impairs parenting skills, which may lead to child maltreatment, insecure attachment, and foster placement (Berlin, Shanahan, \& Carmody, 2014; "“'Sanders \& Russler, 2014).

Research links parental substance abuse with an increased risk for children to engage in substance abuse as adults (Anna et al., 2012). Additionally, children whose mothers used alcohol and illicit drugs during pregnancy had increased risks for long term physical, cognitive, behavioral, and academic problems (Muhuri \& Gfroerer, 2009; Sanders \& Russler, 2014). Mothers with substance abuse issues struggle to provide stable, nurturing environments for their children, and this is compounded by challenging circumstances, including economic and social problems like homelessness and no affordable housing (Nichols et al., 2012; Sanders \& Russler, 2014). Also, many mothers have concurrent mental health difficulties, complex trauma histories, experiences of poverty, histories with the criminal justice system, and experiences of abuse and maltreatment from caregivers and/or partners (Naomi et al., 2018; Stone, 2015). It is imperative to screen, counsel, and engage women in treatment due to long-term adverse effects on the lives of mothers and children.

\subsection{Pregnancy}

Among pregnant women aged 15 to 44, 5\% were using illicit drugs (SAMHSA, 2017b). More specifically, pregnant women aged 15 to 17 , had the highest rates of current illicit drug use, 20.9\%. In addition, of pregnant 
women aged 15 to $17,9.4 \%$ reported current alcohol use and $17.6 \%$ had smoked cigarettes in the past month (Stone, 2015; SAMHSA, 2017b).

The number of women of childbearing age, defined as ages $15-44$, who reported past-month heroin use increased to 109,000 in 2013 - 2014, an increase of 3\% over years 2011 - 2012 (CBHSQ, 2016). Data vary and are unreliable on the number of infants born annually after prenatal substance exposure. Substance use is one of many factors that place the mother and newborn at risk for adverse outcomes (Lefebvre et al., 2010, Sanders 2014). Research data indicate that drug use during pregnancy is usually poly-drug use and involves other social determinants, such as lack of prenatal care, high rates of violence exposure, co-occurrence of other psychiatric problems, inadequate nutrition, and poverty (Jones, 2006).

Following the birth of a child, continued substance use by parents is harmful in multiple ways, especially to young children (Berlin, Shanahan, \& Carmody, 2014). Preterm births were statistically higher among drug-using women (Pinto et al., 2010). The incidence of low birth weight was $30.8 \%$ for the substance user, compared to $8 \%$ for non-users and the risk of placental abruption was higher. Prevention and intervention of maternal substance use is warranted to significantly reduce the long term, serious consequences to the mother, unborn fetus, and child (Wendell, 2013).

\section{Treatment}

Greenfield et al. (2010) suggested that women with substance use disorders are especially vulnerable to health and socioeconomic problems and are less likely than men to seek treatment for addiction. Many women choose not to disclose their drug use, especially during their pregnancies because of shame and embarrassment. In addition, others desire to evade perceived negative judgment for fear of legal and social consequences by delaying or avoiding prenatal care (Stone, 2015; Wendell, 2013). Pregnant women often feel guilty and experience stigma, leading to the expectation of being treated similarly by health care providers (Jones, 2006). It is crucial to encourage women to enter into treatment programs. Mothers who are maintaining recovery through a medically supervised program stay connected to their children. Separation from their children can result in depression, poor recovery outcomes, and diminished senses of identity (Alexander, 2017).

\section{Nursing Considerations}

\subsection{Attitudes and Compassion}

Research has found many healthcare professionals who carry negative views and stigmatizing attitudes toward people who misuse drugs or other substances (Alexander, 2017; Chu \& Galang, 2013; Puskar et al., 2013). Negative attitudes significantly influence the nurse-patient relationship and adversely affect patient outcomes. Experiencing a positive patient encounter increases the likelihood for continuity in care for medical problems and their drug dependency issues. Receiving ongoing medical care to address multiple medical comorbidities will mitigate further risks and complications. What patients are seeking is nonjudgmental and empathetic care from healthcare professionals (Chu \& Galang, 2013).

Nurses sometimes struggle internally with providing optimal care to parenting and pregnant women. Aspects of this conflict include the context of personal biases, mistrust of the patient's shared stories, and views of addiction as a social problem (Painter, 2017; Shaw et al., 2016). Reflection and interaction with the mothers' stories can act as a catalyst for resolving bias. Another is being present to nurture a therapeutic nurse-patient relationship. Sharing and openness creates a positive environment for the relationship to grow. Finally, more experience and exposure with compassion with women experiencing substance use fosters more compassionate healthcare environments (Alexander, 2017).

Nurses interact with patients in diverse settings and play important roles in providing guidance, support, and education for women with substance use disorders. Education on effects of mother and fetus, treatment options, and parenting interventions are most useful. A nonjudgmental approach facilitates more disclosures about drug use and the opportunity to discuss other associated risks (Association of Women's Health, Obstetric and Neonatal Nurses [AWHONN], 2014). Building a trusting relationship that leads to the willing sharing of information may result in proper referral and treatment, resulting in optimal outcomes.

\subsection{Education}

Clinical competencies for working with individuals with substance use disorders or addictions need to be clearly evident in the education of healthcare professionals. Effective integrated care will require a competent workforce capable of addressing mental health needs, including addictions and complex comorbidities, while utilizing a person-centered model (Delaney, Robinson, \& Chafetz, 2013). 
Data are limited on the amount of education devoted to substance use health care in nursing schools (Institute of Medicine [IOM], 2006). One study found that approximately one to five hours was spent over two to four years. While another study found, again, little content covering psychiatric nursing for undergraduate nursing students (IOM, 2006). It is imperative that nurse educators integrate into nursing curriculum content about addiction prevention, overdose, and screening (Painter, 2017). Additionally, knowledge of mental health disorders and crisis interventions, especially in acute care settings, should be an integral part of nursing education (Dewitt, 2003). Comorbidity of mental illness is common among women with substance use and dependence, particularly major depressive disorders. Coexisting mental illness needs to be addressed to increase the likelihood of a successful recovery (Brandon, 2014).

Another essential component of nursing education is the proper screening for substance use. Screening should occur at the initial contact. Nurses should be sensitive to the pregnancy and parenting issues, as women fear punitive consequences, such as loss of custody, threat of incarceration, and loss of social services (Brandon, 2014). One universal screening and brief intervention tool is the Screening, Brief Intervention, and Referral To Treatment (SBIRTT). It requires only a 3-5 minute intervention to assess for early intervention and treatment for individuals at risk for developing substance use disorders and those who need referral to specialty care for substance use disorders (Puskar et al., 2013). Puskar et al. (2013) conducted an in-class education on addiction training for nurses with SBIRRT for undergraduate students. Nursing students reported that it changed the perception of working with patients who use drugs and alcohol. Also, the nursing students felt that their knowledge and skills increased.

\section{Conclusion}

One in five Americans has a diagnosed mental illness and many more suffer from untreated mental illnesses and addictions (National Institute of Mental Health, 2017). Women who are pregnant and/or parenting and misuse substances face unique challenges. The stigma often associated with mental illness must be replaced with an understanding of the disease process and compassionate care through nursing education. Only when a well-informed workforce is treating substance abuse will the journey change for those impacted by addiction.

\section{References}

Anna, A.M., Mericle, A.A., Meyers, K., \& Winters, K.C. (2012). Parental substance use impairment, parenting and substance use disorder risk. Journal of Substance Abuse Treatment, 43, 114-123. https://doi.org/10.1016/j.jsat.2011.10.001

Association of Women's Health, Obstetric and Neonatal Nurses. (2014). Criminalization of pregnant women with substance use disorders. Journal of Obstetric Gynecological Neonatal Nursing, 44(1), 93-35.

Author. Sanders, J. (2014). Substance abuse in women: A multidimensional, evidence-based treatment approach. (Unpublished DNP Project). California State University, Fresno.

Author., Sanders, J. \& Russler, M. (2014, November/December). Substance use in pregnancy: NPS can incorporate key strategies to reduce risk. Nurse Practitioner Perspective, 1(5), 47-49.

Alexander, K. (2017, October/December). A call for compassionate care. Journal of Addictions Nursing, 4(28), 220-223. https://doi.org/10.1097/JAN.0000000000000198

Berlin, L.J., Shanahan, M., \& Carmody, K.A. (2014). Promoting supportive parenting in new mothers with substance-use problems: A pilot randomized trial of residential treatment plus an attachment-based parenting program. Infant Mental Health Journal, 35(1), 81-85. https://doi.org/10.1002/imhj.21427

Brandon, A.H. (2014). Psychosocial interventions for substance use during pregnancy. Journal of Perinatal and Neonatal Nursing, 28(3), 169-177. https://doi.org/10.1097/JPN.0000000000000041

Chu, C., \& Galang, A. (2013). Hospital nurses' attitudes towards patients with a history of illicit drug use. Canadian Nurse, 109(6), 29-34.

Cleveland, L.M., Bonugli, R.J., \& McGlothen, K.S. (2016). The mothering experiences of women with substance use disorders. Advances in Nursing Science, 39(2), 119-129. https://doi.org/10.1097/ANS.0000000000000118

Delaney, K.R., Robinson, K.M., \& Chafetz, L. (2013). Development of integrated mental health care: Critical workforce competencies. Nursing Outlook, 61(6), 384-391. https://doi.org/10.1016/j.outlook.2013.03.005

Dewitt, G. (2003). Why nurses? Nurses and volunteering: A perfect match. Retrieved from http://www.serviceleader.org/instructors/studentpaper11 
Grant, B.F., Saha, T.D., Ruan, W.J., Goldstein, R.B., Chou, S.P., Jung, J., ... Hasin, D.S. (2016). Epidemiology of DSM-5 drug use disorder results from the National Epidemiologic Survey on Alcohol and Related Conditions-III. Journal of the American Medical Association Psychiatry, 73(1), 39-47. https://doi.org/10.1001/jamapsychiatry.2015.2132

Greenfield, S.F., Back, S.E., Lawson, K., \& Brady, K.T. (2010). Substance abuse in women. Psychiatry Clinics of North America, 33(2), 339-355. https://doi.org/10.1016/j.psc.2010.01.00

Grella, C.E. (2008). From generic to gender-responsive treatment: Changes in social policies, treatment services, and outcomes of women in substance abuse treatment. Journal of Psychoactive Drugs, 40(5), 327-343. https://doi.org/10.1080/02791072.2008.10400661

Grosso, J.A., Epstein, E.E., McCrady, B., Gaba, A., Cook, S., Backer-Fulghum, L.M., ... Graff, F.S. (2012). Women's motivators for seeking treatment for alcohol use disorders. Addictive Behaviors, 38, 2236-2245.

Institute of Medicine: Committee on Crossing the Quality Chasm. (2006). Adaptation to mental health and addictive disorders. Improving the quality of health care for mental and substance-use conditions. Quality Chasm Series. Washington (DC): National Academies Press. https://doi.org/10.17226/11470

Jones, H. (2006). Drug addiction during pregnancy: Advances in maternal treatment and understanding child outcomes. Current Direction in Psychological Science, 15(3), 126-130. https://doi.org/10.1111/j.0963-7214.2006.00421.x

Lefebvre, L., Midner, D., Boyd, J.A., Ordean, A., Graves, L., Kahan, M., \& Pantea, L. (2010). Participant perception of an integrated program for substance abuse in pregnancy. Journal of Gynecology, Obstetrics, and Neonatal Nursing, 39, 46-52. https://doi.org/10.1111/j.1552-6909.2009.01083.x

McHugh, R.K., Votawa, V.R., Sugarman, D.E., \& Greenfield, S.F. (2017). Sex and gender differences in substance use disorders. Clinical Psychology Review, 25(3), 101-102. https://doi.org/10.1016/j.cpr.2017.10.012

Muhuri, P.K., \& Gfroerer, J.C. (2009). Substance use among women: Associations with pregnancy, parenting, and race/ethnicity. Maternal Child Health, 13, 376-385. https://doi.org/10.1007/s10995-008-0375-8

Naomi, C.Z., Andrews, C.Z. Motza, M., Peplerb, D.J., Jeongb, J.J., \& Khoury, J. (2018, September). Child abuse \& neglect. Engaging Mothers With Substance Use Issues and Their Children in Early Intervention: $\begin{array}{lllll}\text { Understanding Use of Service and Outcomes, } & \text { 83, }\end{array}$ https://doi-org.hmlproxy.lib.csufresno.edu/10.1016/j.chiabu.2018.06.011

National Center on Addiction and Drug Use at Columbia University. (2012, July). Addiction Medicine: Closing the Gap Between Science and Practice. Retrieved from https://www.centeronaddiction.org/addiction-research/reports/addiction-medicine-closing-gap-between-scie nce-and-practice

National Institute of Mental Health. (2017, November). Mental illness. Retrieved from https://www.nimh.nih.gov/health/statistics/mental-illness.shtml

National Institute on Drug Abuse. (2018, June). Substance Use in Women. Retrieved from https://www.drugabuse.gov/related-topics/women-drugs

National Institute on Drug Addiction. (2012). Principle of drug addiction treatment: A research-based guide (3rd ed.). Retrieved from http://www.drugabuse/gov/sites/default/files/podat_1.pdf

Nichols, A., Milligan, K., Smith, A., Sword, W., Thabane, L., \& Henderson, J. (2012). Integrated programs for mothers with substance abuse issues and their children: A systematic review of studies reporting on child outcomes. Child Abuse \& Neglect, 36(4), 308-322. https://doi.org/10.1016/j.chiabu.2011.10.007

Office on Women's Health. (2017, January). Final report: Opioid use, misuse, and overdose in women. Retrieved from https://www.womenshealth.gov/files/documents/white-paper-opioid-508.pdf

Painter, S.G. (2017, May). Opiate crisis and healthcare reform in America: A review for nurses. The Online Journal of Issues in Nursing, 22(2). Retrieved from http://ojin.nursingworld.org/MainMenuCategories/ANAMarketplace/ANAPeriodicals/OJIN/TableofConten ts/Vol-22-2017/No2-May-2017/Opiate-Crisis-and-Healthcare-Reform-in-America.html

Pinto, S.M., Dodd, S., Walkinshaw, S.A., Siney, C., Kakkar, P., \& Mousa, H.A. (2010). Substance abuse during pregnancy: Effect on pregnancy outcomes. European Journal of Obstetrics \& Gynecology and Reproductive Biology, 150, 137-141. https://doi.org/10.1016/j.ejogrb.2010.02.026 
Puskar, K., Gotham, H.J, Terhorst, L., Hagle, H., Mitchell, A.M, Braxter B., ... Burns, H.K. (2013). Effects of screening, brief intervention, and referral to treatment (SBIRT) education and training on nursing students' attitudes toward working with patients who use alcohol and drugs. Substance Use, 34, 122-128.

Seedat, S., Scott, K.M., Angermeyer, M.C., Berglund, P., Bromet, E.J., Brugha, T.S., .. Kessler, R.C. (2009). Cross-national associations between gender and mental disorders in the World Health Organization world mental health surveys. Archives of General Psychiatry, 66(7), 785-795. https://doi.org/10.1001/archgenpsychiatry.2009.36

Shaw, M.R., Lederhos, C., Haberman, M., Howell, D., Fleming S., \& Roll J. (2016). Nurses' perceptions of caring for childbearing women who misuse opioids. The American Journal of Maternal Child Nursing, $41(1), 37-42$.

Stone, R. (2015). Pregnant women and substance use: Fear, stigma, and barriers to care. Health and Justice, 3(2). https://doi.org/10.1186/s40352-015-0015-5

Substance Abuse and Mental Health Services Administration. (2017a). Key substance use and mental health indicators in the United States: Results from the 2016 National Survey on Drug Use and Health (HHS Publication No. SMA 17-5044, NSDUH Series H-52). Rockville, MD: Center for Behavioral Health Statistics and Quality, Substance Abuse and Mental Health Services Administration. Retrieved from https://www.samhsa.gov/data/report/key-substance-use-and-mental-health-indicators-united-states-results-2 016-national-survey

Substance Abuse and Mental Health Services Administration. (2017b). Results from the 2016 National Survey on Drug Use and Health: Detailed Tables. Retrieved from https://www.samhsa.gov/data/sites/default/files/NSDUH-DetTabs-2016/NSDUH-DetTabs-2016.pdf

Wendell, A.D. (2013). Overview and epidemiology of substance abuse pregnancy. Clinical Obstetrics and Gynecology, 56(1), 91-96. https://doi.org/10.1097/GRF.0b013e31827feeb9

Young, B.B. (2010). Using the tidal model of mental health recovery to plan primary health care for women in residential substance abuse recovery. Issues in Mental Health Nursing, 31, 569-575. https://doi.org/10.3109/01612840.2010.487969

\section{Copyrights}

Copyright for this article is retained by the author(s), with first publication rights granted to the journal.

This is an open-access article distributed under the terms and conditions of the Creative Commons Attribution license (http://creativecommons.org/licenses/by/4.0/). 